\title{
Edit Check Program
}

National Cancer Institute

\section{Source}

National Cancer Institute. Edit Check Program. NCI Thesaurus. Code C115482.

A computer application that satisfies the edit check specification details in the data validation process. 